\title{
Preparation and Properties of Ag-Containing Diamond-Like Carbon Films by Magnetron Plasma Source Ion Implantation
}

\author{
K. Baba, ${ }^{1}$ R. Hatada, ${ }^{2}$ S. Flege, ${ }^{2}$ and W. Ensinger ${ }^{2}$ \\ ${ }^{1}$ Industrial Technology Center of Nagasaki, Applied Technology Division, Omura, Nagasaki 856-0026, Japan \\ ${ }^{2}$ Department of Materials Science, Technische Universität Darmstadt, 64287 Darmstadt, Germany \\ Correspondence should be addressed to K. Baba, baba@tc.nagasaki.go.jp
}

Received 27 April 2011; Revised 31 July 2011; Accepted 2 August 2011

Academic Editor: Robert G. Elliman

Copyright $\odot 2012 \mathrm{~K}$. Baba et al. This is an open access article distributed under the Creative Commons Attribution License, which permits unrestricted use, distribution, and reproduction in any medium, provided the original work is properly cited.

\begin{abstract}
The doping effect of silver on the structure and properties of diamond-like carbon (DLC) films was investigated. The samples were prepared by a process combining acetylene plasma source ion implantation (high-voltage pulses of $-10 \mathrm{kV}$ ) with reactive magnetron sputtering of an Ag disc. A mixture of two gases, argon, and acetylene was introduced into the discharge chamber as working gas for plasma formation. A negative high-voltage pulse was applied to the substrate holder, thus, accelerating ions towards the substrate. The chemical composition of the deposited films was modified by the respective gas flows and determined using Xray photoelectron spectroscopy and secondary ion mass spectrometry. The silver concentration within the DLC films influenced the structure and the tribological properties. The surface roughness, as observed by scanning electron microscopy, increased with silver concentration. The film structure was characterized by Raman spectroscopy and X-ray diffractometry (XRD). The DLC films were mainly amorphous, containing crystalline silver, with the amount of silver depending on the process conditions. The tribological properties of the films were improved by the silver doping. The lowest friction coefficient of around 0.06 was derived at a low silver content.
\end{abstract}

\section{Introduction}

Plasma source ion implantation (PSII) is a simple but effective ion implantation and deposition method for surface modification of materials [1-3]. In the PSII process, a negative high-voltage pulse is applied directly to a target, and thus a plasma is generated in front of the substrate. The ions from the plasma forming gases such as nitrogen, oxygen, or hydrocarbons are implanted into the substrate surface. This has been reported to improve several parameters such as hardness, adhesion, friction coefficient, and wear properties [4-11].

Furthermore, it is possible to implant metal ions by PSII or to deposit films. If PSII is combined with a conventional sputtering process, the element sputtered from the target does not only form a film on top of the substrate but is also implanted into the substrate [12]. Hence, a mixed zone at the interface is formed thereby improving the adhesion of the film. PSII can also be applied to deposit diamond-like carbon (DLC) films, for example, by altering experimental parameters such as the pulse voltage and length and by using acetylene as working gas [9]. Here, the incorporation of other elements into the DLC films offers the possibility to modify the properties of the DLC films. Again, this is feasible by a combined process. Since both processes (sputtering and PSII) are run simultaneously in a single experimental chamber, a mixture of a hydrocarbon gas and argon has to be used. The argon ions are used to sputter material from the cathode whereas the hydrocarbons from the plasma function as a source for deposition of a DLC film, resulting in a compound film $[12,13]$. Metalcontaining DLC films with properties intermediate between DLC and metal carbides have been shown to improve the adhesion and hardness as well as the wear properties. This is due to the microstructure of the films comprising nanocrystalline grains in an amorphous carbon matrix [1416]. The incorporation of silver into DLC films (Ag-DLC) is of interest as it offers the possibility to reduce the internal stress [17], to enhance the wear properties [18], and because it provides films that are haemocompatible and antibacterial [19-21]. 


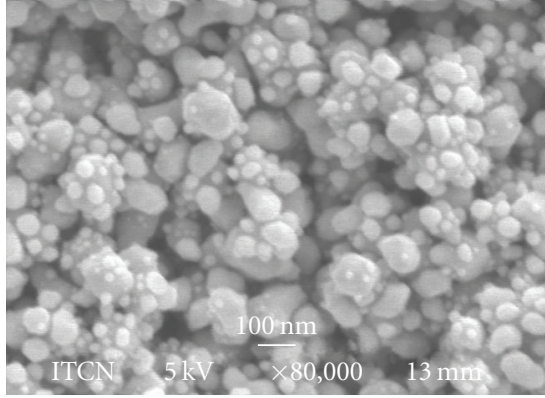

61.3 at. $\% \mathrm{Ag}$

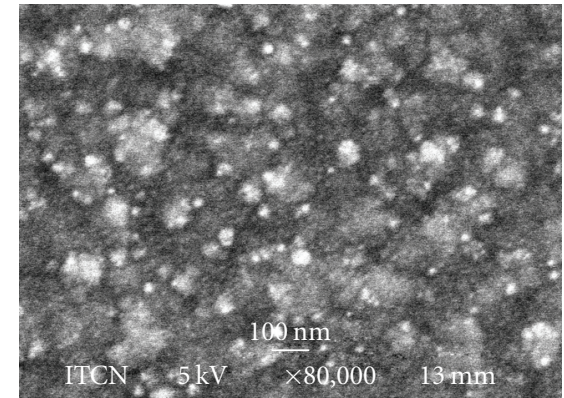

13.4 at. $\% \mathrm{Ag}$

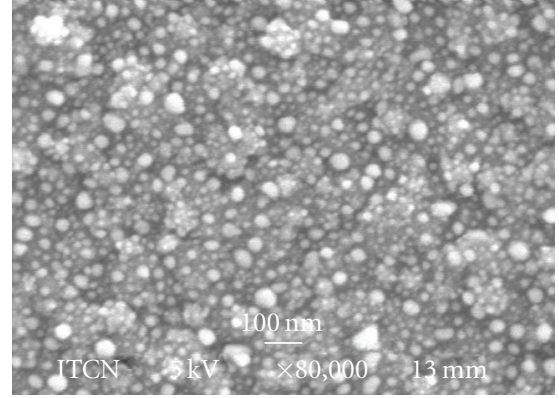

5.9 at. \% Ag

(a)

(b)

(c)

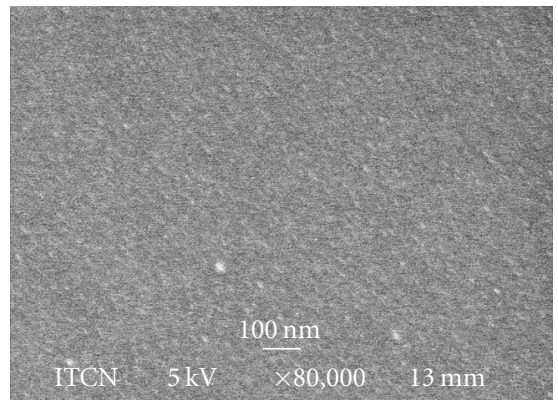

4.5 at. $\% \mathrm{Ag}$

(d)

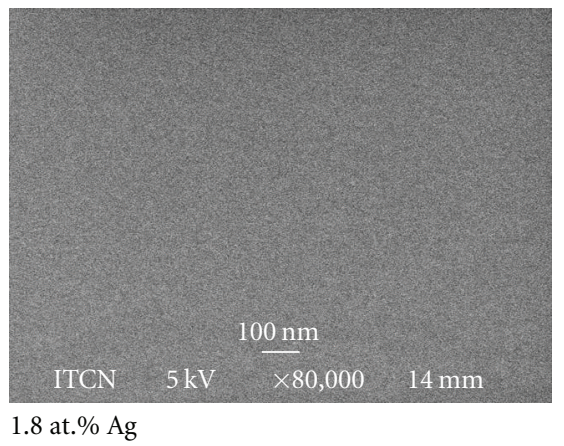

(e)

FIGURE 1: SEM images of the surfaces of silver-containing DLC films.

In our previous works, we have reported on the plasma source implantation of sputtered $\mathrm{Ni}$ ions into materials and the effects of metal ( $\mathrm{Ti}, \mathrm{Ta}, \mathrm{Fe}, \mathrm{Co}, \mathrm{Ni}, \mathrm{Mo}$, and $\mathrm{W}$ ) incorporation into DLC films on the composition, structure, and phase formation $[12,13,22]$. In this study, the influence of the silver content in DLC films prepared by a combined magnetron sputtering and PSII process on the structure, surface roughness, and tribological properties of the films is discussed.

\section{Experimental}

The silver containing Ag-DLC films were deposited on silicon wafer substrates (100) using a PSII method combined with magnetron sputtering. Details of the magnetron plasma source ion implantation apparatus used in this study are described in detail elsewhere [22]. The base pressure in the chamber was $10^{-4} \mathrm{~Pa}$. Argon and acetylene $\left(\mathrm{C}_{2} \mathrm{H}_{2}\right)$ were let into the vacuum chamber by controlling their flow through mass flow controllers. The film composition was altered by changing the flow rate of the acetylene gas between 2.1 and $5.6 \mathrm{sccm}$ while keeping the argon flow rate fixed at $20 \mathrm{sccm}$. The vacuum pressure during implantation was set to around $1 \mathrm{~Pa}$. An Ag disc with four inches $(10 \mathrm{~cm})$ in diameter was used as the sputtering target. The plasma was generated by the application of a $13.56 \mathrm{MHz}, 150 \mathrm{~W}$ rf power to the magnetron sputter source. A pulse voltage of $-10 \mathrm{kV}$ superposed to a DC voltage of $-2 \mathrm{kV}$ was applied to the substrate holder at a pulse repetition rate of $100 \mathrm{~Hz}$ and a pulse duration of $100 \mu$ s. The process times were between 0.2 and $1 \mathrm{~h}$. The thickness of the films was monitored by cross-sectional scanning electron microscopy (SEM) observation. The surface morphology of the films was also observed by SEM. The chemical composition and chemical state of the films were evaluated using X-ray photoelectron spectroscopy (XPS) under $\mathrm{Mg} \mathrm{K} \alpha \mathrm{X}$-ray irradiation. Depth profiles were obtained by secondary ion mass spectrometry using $3.5 \mathrm{keV} \mathrm{O}_{2}{ }^{+}$primary ions detecting positive secondary ions. The structural information was studied by X-ray diffractometry (XRD) with $\Theta-2 \Theta$ configuration and Raman spectroscopy with an excitation wavelength of $514 \mathrm{~nm}$ of an argon ion laser.

A ball-on-disc type apparatus was employed for the tribological tests using balls of tungsten carbide with $6 \mathrm{~mm}$ diameter. Friction coefficients were determined with a normal load of $2 \mathrm{~N}$ and a velocity of $100 \mathrm{~mm} / \mathrm{s}$. The tests were carried out at room temperature and at about $25 \%$ relative humidity.

\section{Results and Discussion}

The silver content in the films depended on the volume fraction of $\mathrm{C}_{2} \mathrm{H}_{2}$ in the $\mathrm{C}_{2} \mathrm{H}_{2} / \mathrm{Ar}$ gas mixture. For the lowest flow rate of $\mathrm{C}_{2} \mathrm{H}_{2}$, a silver content of 61.3 at.\% was found, as determined by XPS, with decreasing Ag content for increasing $\mathrm{C}_{2} \mathrm{H}_{2}$ flow rate, for example, $1.8 \mathrm{at} \% \mathrm{Ag}$ at $3.5 \mathrm{sccm}$. The concentration of the metal in the DLC films could be controlled by changing the fraction of $\mathrm{C}_{2} \mathrm{H}_{2}$ in the gases. Similar results were reported for W-containing DLC $[13,23]$. The thicknesses of the films were $0.5-1 \mu \mathrm{m}$. The surface morphology as observed by SEM is shown in Figure 1. A very smooth structure was observed for the lower 


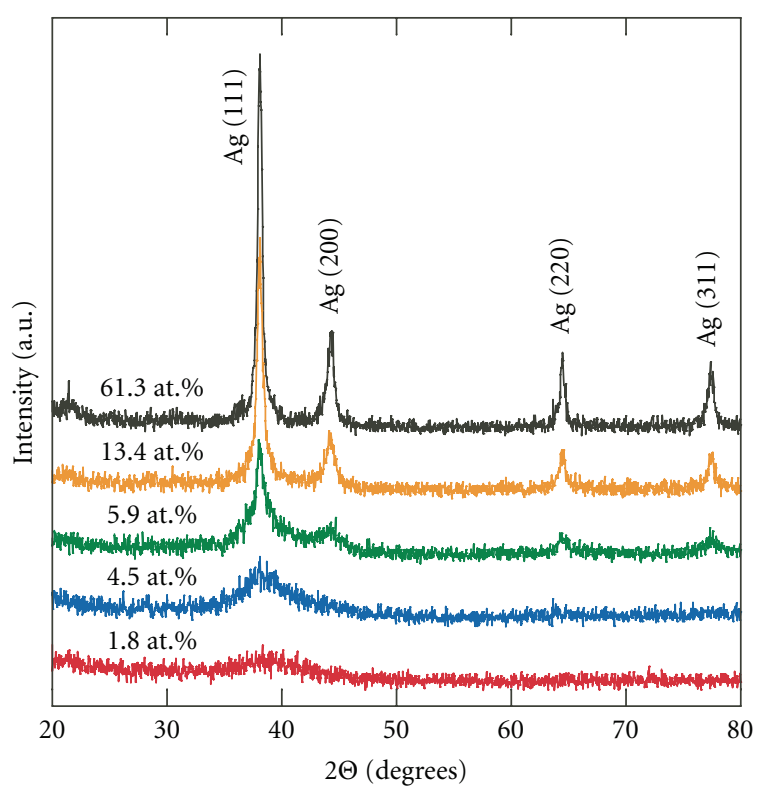

FIGURE 2: X-ray diffractograms of silver-containing DLC films with increasing amount of silver.

contents of silver, that is, 1.8 at. $\%$ and 4.5 at. $\%$ Ag. For the higher-content Ag-containing films, an increasing grain size with a corresponding higher surface roughness was found (Figure 1).

Figure 2 shows XRD patterns for Ag-DLC films with an increasing amount of silver. At a silver concentration of 1.8 at.\%, there is only a weak broad reflex at $38.27^{\circ}$. From the peak width, a crystallite size of $4.8 \mathrm{~nm}$ was estimated. For a different preparation technique, it was reported that $\mathrm{Ag}$ atoms began to form an amorphous silver phase in the amorphous carbon matrix for a silver concentration of 1.8 at. $\%$ [17]. With a concentration of $\mathrm{Ag}$ of 5.9 at. $\%$ or higher several reflexes are found which can be assigned to the Ag crystalline phase. The intensity of the reflexes increased with the silver content in the films. Since silver is not capable of forming a carbide, there are Ag clusters within the carbon matrix [14].

Raman measurements were performed to investigate the chemical structure of the Ag-DLC films. A typical broad peak for the DLC films was observed at a range between $1000 \mathrm{~cm}^{-1}$ and $1800 \mathrm{~cm}^{-1}$ for all films. The Raman spectra show two prominent features: the D (disorder) line around $1350 \mathrm{~cm}^{-1}$ and the $\mathrm{G}$ (graphite) line around $1580-1600 \mathrm{~cm}^{-1}$ $[24,25]$. The spectral profile was fitted by two Gaussian profiles corresponding to the $\mathrm{D}$ line and $\mathrm{G}$ line, and the integrated intensity ratio $\left(I_{\mathrm{D}} / I_{\mathrm{G}}\right)$ was calculated.

The Raman spectrum and the parameters, peak positions, full widths at half maximum (FWHM), and the ratio of $I_{\mathrm{D}} / I_{\mathrm{G}}$ of the Ag-DLC films containing different amounts of silver are shown in Figure 3 and Table 1. The FWHM is correlated with the amount of disorder and corresponds to the crystalline size of the $\mathrm{sp}^{2}$-bonded carbon [26]. The broad peak did not change for Ag concentrations up to 4.5 at.\%. With higher silver content in the film, the broad peak separated into two peaks at around $1600 \mathrm{~cm}^{-1}$ and at

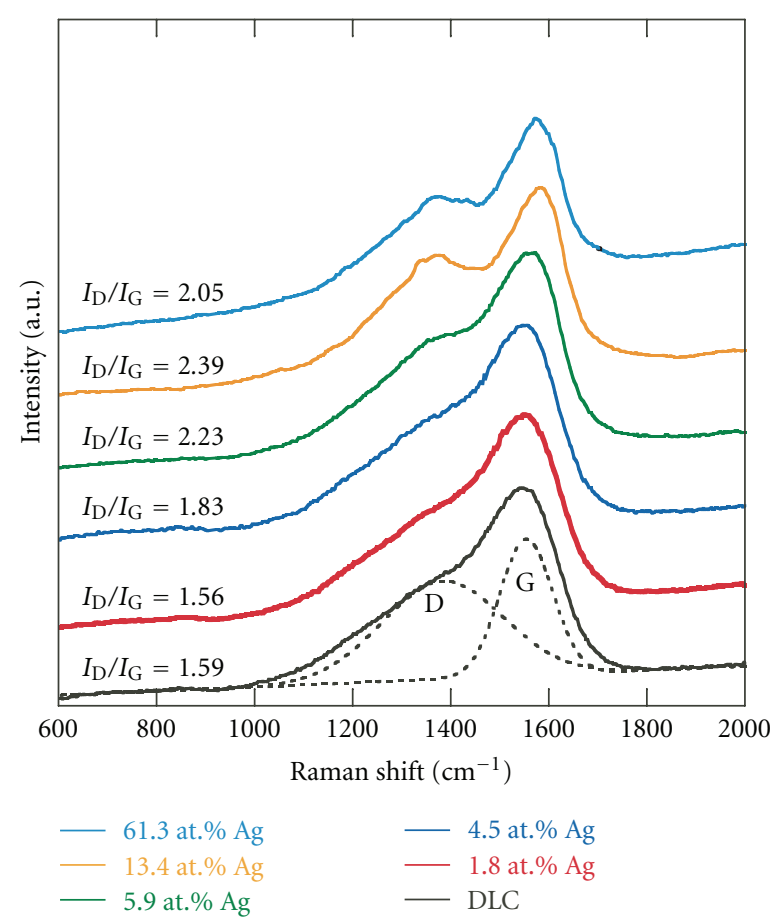

Figure 3: Raman spectra of Ag-DLC films containing different amounts of silver.

around $1360 \mathrm{~cm}^{-1}$ as shown in Figure 3. The G line exhibited a shift to higher frequencies from 1553 to $1578 \mathrm{~cm}^{-1}$ and a reduction of the FWHM.

For an Ag-free DLC film, the $I_{\mathrm{D}} / I_{\mathrm{G}}$ ratio was 1.6 , and, for Ag-DLC films, the values of the ratio were between 1.6 and 2.4. The addition of silver to the DLC film leads to a narrower $G$ peak and a higher intensity ratio, which can be attributed to an increase of the average crystalline size of $\mathrm{sp}^{2}$-bonded clusters [24]. An additional influence of the varying bombardment conditions on the Raman spectra is also possible.

The SIMS depth profiles for the 4.5 at.\% Ag-DLC and the 61.3 at.\% Ag-DLC films are presented in Figure 4. Since the plasma in acetylene PSII also contains hydrogen atomic ions and carbon-hydrogen molecular ions, there is a certain amount of hydrogen within the DLC films. The carbon and hydrogen signals are constant within the DLC layer. Ag could be found throughout the DLC layer with a nearly constant intensity. With increasing Ag content, the intensity ratio of $\mathrm{C} / \mathrm{Ag}$ decreases accordingly. With the hydrogen, the situation is different, however. The H/Ag intensity ratio is roughly constant for all Ag concentrations; hence, the H/C intensity ratio is increasing with Ag content. Whether this reflects a real increase in $\mathrm{H}$ concentration is difficult to say from the measurements done so far since SIMS intensities usually do not permit quantitative statements. The ${ }^{16} \mathrm{O}$ signal is at least partly from the implanted primary ions, that is, this is not a feature of the original DLC film. For the 61.3 at.\% AgDLC films, it takes some sputtering time until the signals are stable; the transition towards the substrate is also not as 
TABLE 1: Raman spectroscopy data of Ag-DLC films with various amounts of silver.

\begin{tabular}{|c|c|c|c|c|c|c|}
\hline Sample No. & $\mathrm{C}_{2} \mathrm{H}_{2}$ flow rate & $\begin{array}{c}\text { Deposition rate } \\
(\mathrm{nm} / \mathrm{min})\end{array}$ & $\begin{array}{c}\text { Ag concentration } \\
\text { (at. } \%)\end{array}$ & $\begin{array}{c}\text { G band peak } \\
\left(\mathrm{cm}^{-1}\right)\end{array}$ & $\begin{array}{l}\text { FWHM } \\
\left(\mathrm{cm}^{-1}\right)\end{array}$ & $I_{\mathrm{D}} / I_{\mathrm{G}}$ \\
\hline 1 & 2.10 & 39.5 & 61.3 & 1578.6 & 111.0 & 2.05 \\
\hline 2 & 1.75 & 15.3 & 32.5 & 1588.2 & 115.0 & 2.26 \\
\hline 3 & 2.80 & 13.2 & 13.4 & 1584.0 & 113.1 & 2.39 \\
\hline 4 & 3.15 & 9.4 & 5.9 & 1566.3 & 129.7 & 2.23 \\
\hline 5 & 3.50 & 13.4 & 4.5 & 1555.5 & 144.9 & 1.83 \\
\hline 6 & 3.50 & 16.0 & 1.8 & 1557.0 & 151.8 & 1.56 \\
\hline 7 & 5.60 & 21.6 & 0 & 1553.6 & 153.6 & 1.59 \\
\hline
\end{tabular}

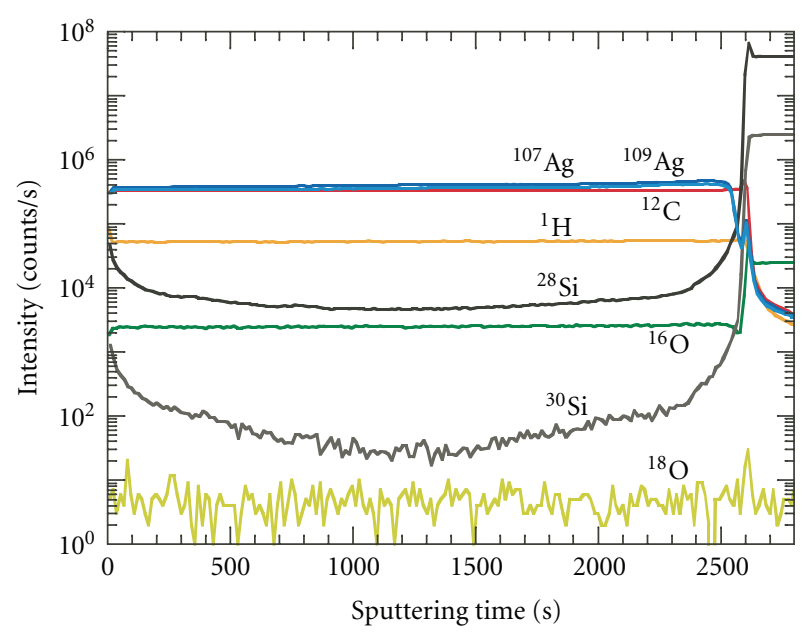

(a)

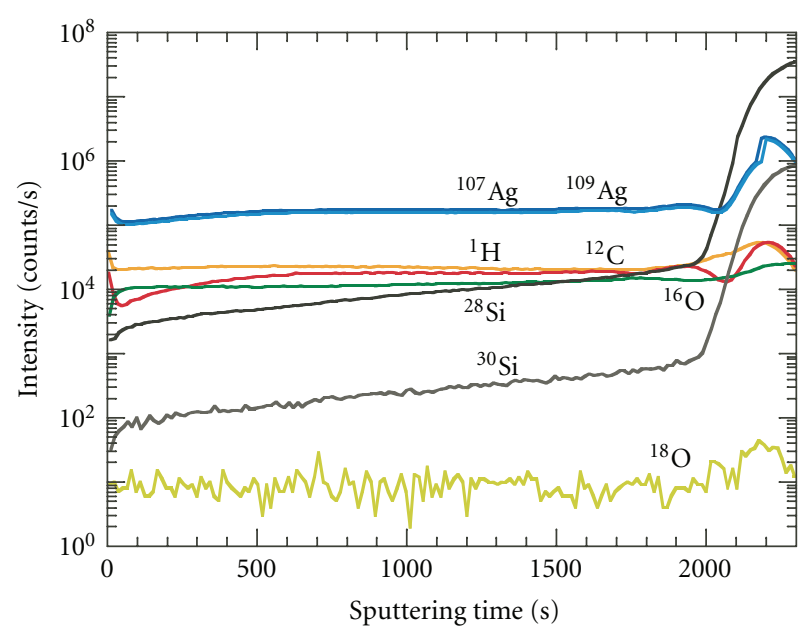

(b)

FIGURE 4: Secondary ion mass spectrometry depth profiles of (a) 4.5 at.\% silver and (b) 61.3 at.\% silver-incorporated DLC films.

sharp as in the case of the other profile. This is due to the much higher surface roughness of the Ag-rich sample (see Figure 1).

Figure 5 shows the results of the ball-on-disc tests in dry conditions for the Ag-free film and several Ag containing films. A small addition of silver decreased the friction

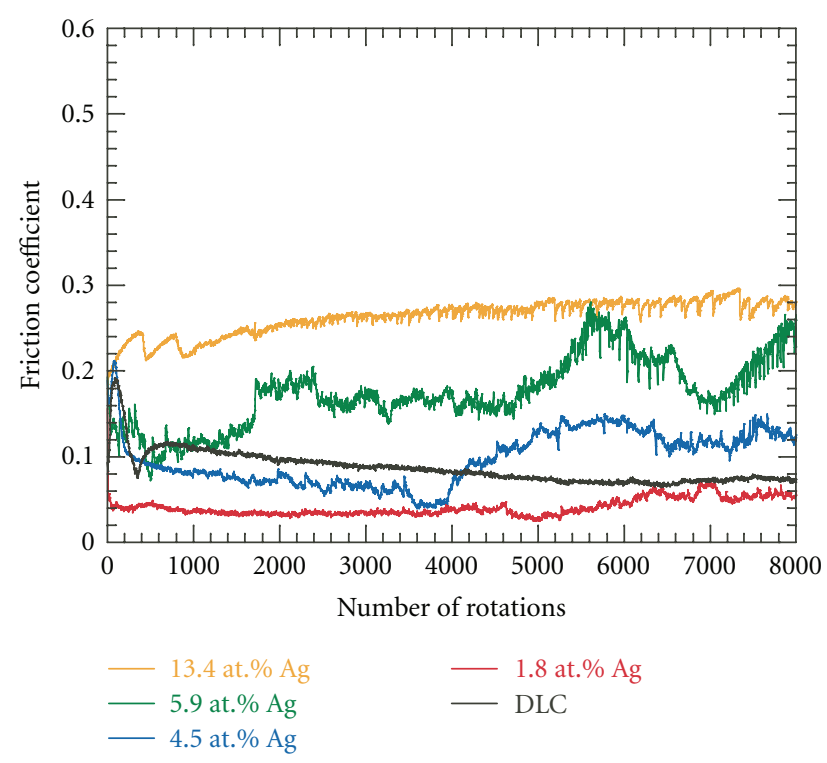

FIGURE 5: Friction coefficient as a function of rotations in the ballon-disk tests of silver-containing DLC films.

coefficient as compared to the Ag-free film. With higher concentrations of silver, the friction coefficient increased from 0.06 to 0.28 with increasing $\mathrm{Ag}$ concentration in the film. With the 1.8 at.\% Ag-DLC film, the friction coefficient was around 0.06 at the beginning of the test, and stable for several thousand rotations. The surface of this film was relatively smooth, and section profiles of the sliding traces of this film after the wear test showed only a very fine wear track. Choi et al. [17] reported the existence of amorphous silver phase precipitates with a size of $2 \mathrm{~nm}$ in the amorphous carbon matrix from transmission electron microscopy. In this study, XRD measurement suggested a composite structure of nanocrystalline $\mathrm{Ag} /$ amorphous DLC for the 1.8 at.\% Ag-containing film. So the tribological behavior can be improved by silver addition to the film, which can be attributed to the nanoscale grain size structure of the film. This is also valid for higher Ag contents [18].

\section{Conclusions}

Silver-containing DLC films were successfully prepared by a process combining reactive magnetron sputtering with 
plasma source ion implantation. The content of silver in the DLC films could be controlled by setting the flow rates of the involved argon and acetylene gases. Silver atoms were incorporated over the whole depth of the DLC films, but tended to agglomerate. The structure and tribological properties were affected by the Ag content of the DLC films. The DLC structure of the films changed with deposition conditions as seen by the Raman spectra (separation of one broad peak into two peaks for the silver-containing DLC films). The surface roughness increased with the silver content in the films. The best wear property was derived for the 1.8 at.\% silver-containing DLC film and showed an improvement as compared to the Ag-free film. Investigations about the antibacterial activity for use in biological applications are underway and will be presented elsewhere.

\section{References}

[1] J. R. Conrad and T. Castagna, "Plasma Source Ion Implantation for Surface Modification," Bulletin of the American Physical Society, vol. 31, p. 1429, 1986.

[2] J. R. Conrad, "Sheath thickness and potential profiles of ion-matrix sheaths for cylindrical and spherical electrodes," Journal of Applied Physics, vol. 62, no. 3, pp. 777-779, 1987.

[3] J. Tendys, I. J. Donnelly, M. J. Kenny, and J. T. A. Pollock, "Plasma immersion ion implantation using plasmas generated by radio frequency techniques," Applied Physics Letters, vol. 53, no. 22, pp. 2143-2145, 1988.

[4] K. C. Walter, R. A. Dood, and J. R. Conrad, "Corrosion behavior of nitrogen implanted aluminum," Nuclear Instruments and Methods in Physics Research Section B, vol. 106, no. 1-4, pp. 522-526, 1995.

[5] A. Chen, X. Qiu, K. Sridharan et al., "Chromium plating pollution source reduction by plasma source ion implantation," Surface and Coatings Technology, vol. 82, no. 3, pp. 305-310, 1996.

[6] B. Y. Tang, P. K. Chu, S. Y. Wang, K. W. Chow, and X. F. Wang, "Methane and nitrogen plasma immersion ion implantation of titanium metal," Surface and Coatings Technology, vol. 103104, pp. 248-251, 1998.

[7] S. Han, H. Kim, Y. Lee, J. Lee, and S.-G. Kim, "Plasma source ion implantation of nitrogen, carbon and oxygen into Ti-6A14V alloy," Surface and Coatings Technology, vol. 82, no. 3, pp. 270-276, 1996.

[8] K. C. Walter, M. Nastasi, N. P. Baker et al., "Advances in PSII techniques for surface modification," Surface and Coatings Technology, vol. 103-104, no. 1, pp. 205-211, 1998.

[9] K. Baba and R. Hatada, "Deposition of diamond-like carbon films on polymers by plasma source ion implantation," Thin Solid Films, vol. 506-507, pp. 55-58, 2006.

[10] J. Chen, J. Blanchard, J. R. Conrad, and R. A. Dodd, "Structure and wear properties of carbon implanted 304 stainless steel using plasma source ion implantation," Surface and Coatings Technology, vol. 53, no. 3, pp. 267-274, 1992.

[11] J. Chen, J. R. Conrad, and R. A. Dodd, "Methane plasma source ion implantation (PSII) for improvement of tribological and corrosion properties," Journal of Materials Processing Technology, vol. 49, no. 1-2, pp. 115-124, 1995.

[12] K. Baba and R. Hatada, "Preparation and properties of metalcontaining diamond-like carbon films by magnetron plasma source ion implantation," Surface and Coatings Technology, vol. 196, no. 1-3, pp. 207-210, 2005.
[13] K. Baba and R. Hatada, "Preparation and properties of metal containing diamond-like carbon films by magnetron plasma source ion implantation," Surface and Coatings Technology, vol. 158-159, pp. 373-376, 2002.

[14] C. P. Klages and R. Memming, "Microstructure and physical properties of metal-containing hydrogenated carbon films," Materials Science Forum, vol. 52-53, p. 609, 1990.

[15] C. Donnet, "Recent progress on the tribology of doped diamond-like and carbon alloy coatings: a review," Surface and Coatings Technology, vol. 100-101, no. 1-3, pp. 180-186, 1998.

[16] A. A. Voevodin, S. V. Prasad, and J. S. Zabinski, "Nanocrystalline carbide/amorphous carbon composites," Journal of Applied Physics, vol. 82, no. 2, pp. 855-858, 1997.

[17] H. W. Choi, J. H. Choi, K. R. Lee, J. P. Ahn, and K. H. $\mathrm{Oh}$, "Structure and mechanical properties of Ag-incorporated DLC films prepared by a hybrid ion beam deposition system," Thin Solid Films, vol. 516, no. 2-4, pp. 248-251, 2007.

[18] C. P. Lungu, I. Mustata, G. Musa et al., "Formation of nanostructured Re-Cr-Ni diffusion barrier coatings on $\mathrm{Nb}$ superalloys by TVA method," Surface and Coatings Technology, vol. 200, no. 1-4, pp. 399-402, 2005.

[19] J. L. Endrino, R. E. Galindo, H.-S. Zhang et al., "Structure and properties of silver-containing a-C(H) films deposited by plasma immersion ion implantation," Surface and Coatings Technology, vol. 202, no. 15, pp. 3675-3682, 2008.

[20] H. W. Choi, R. H. Dauskardt, S.-C. Lee, K. R. Lee, J. P. Ahn, and K. H. Oh, "Characteristic of silver doped DLC films on surface properties and protein adsorption," Diamond and Related Materials, vol. 17, no. 3, pp. 252-257, 2008.

[21] J. Wang, N. Huang, C. J. Pan et al., "Bacterial repellence from polyethylene terephthalate surface modified by acetylene plasma immersion ion implantation-deposition," Surface and Coatings Technology, vol. 186, no. 1-2, pp. 299-304, 2004.

[22] K. Baba and R. Hatada, "Deposition and characterization of Ti- and W-containing diamond-like carbon films by plasma source ion implantation," Surface and Coatings Technology, vol. 169-170, pp. 287-290, 2003.

[23] A.-Y. Wang, K.-R. Lee, J.-P. Ahn, and J. H. Han, "Structure and mechanical properties of $\mathrm{W}$ incorporated diamond-like carbon films prepared by a hybrid ion beam deposition technique," Carbon, vol. 44, no. 9, pp. 1826-1832, 2006.

[24] J. Robertson, "Diamond-like amorphous carbon," Materials Science and Engineering, vol. 37, pp. 129-281, 2002.

[25] A. C. Ferrari and J. Robertson, "Interpretation of Raman spectra of disordered and amorphous carbon," Physical Review B, vol. 61, no. 20, pp. 14095-14107, 2000.

[26] C. Casiraghi, A. C. Ferrari, and J. Robertson, "Raman spectroscopy of hydrogenated amorphous carbons," Physical Review B, vol. 72, Article ID 085401, 14 pages, 2005. 

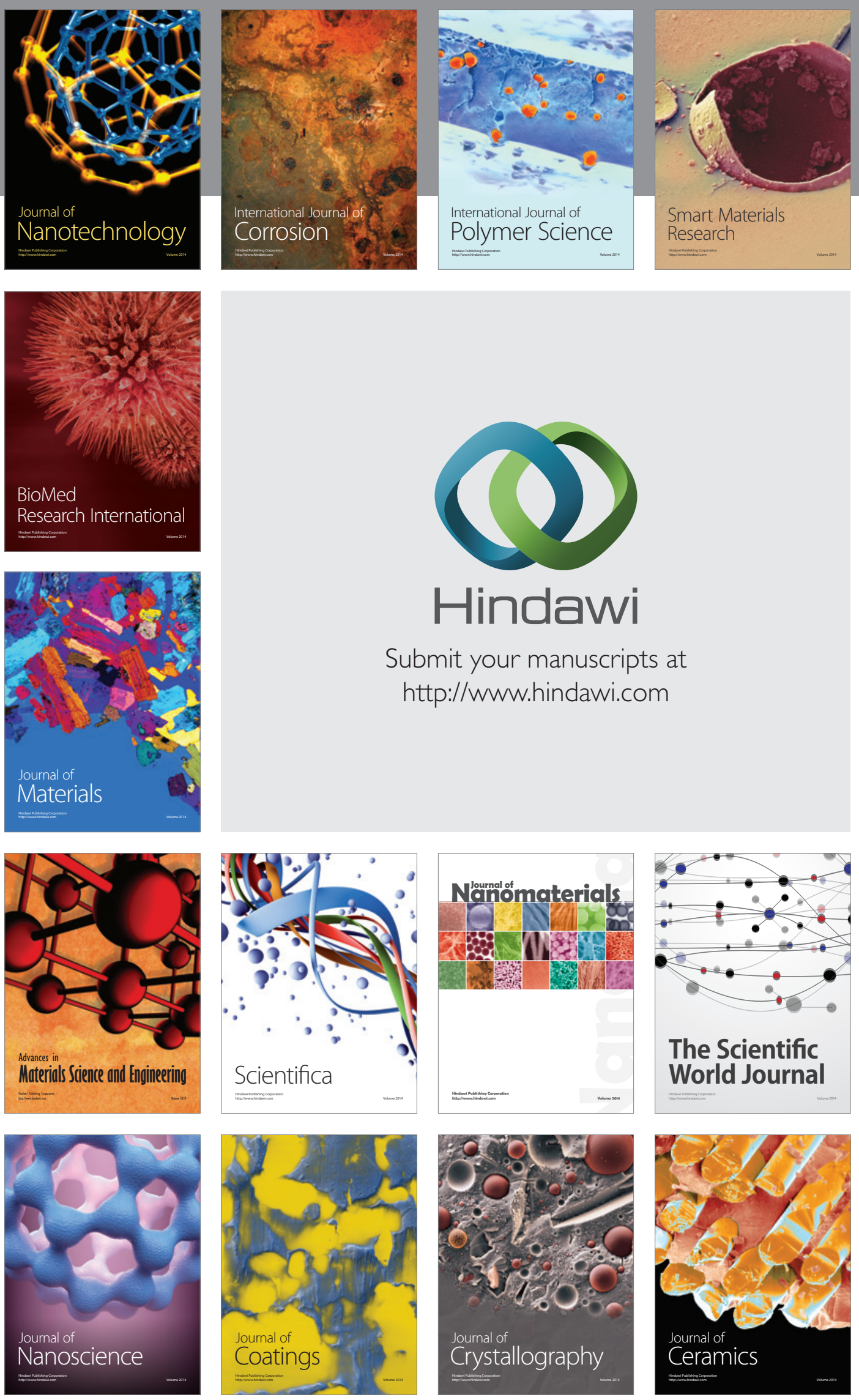

The Scientific World Journal

Submit your manuscripts at

http://www.hindawi.com

\section{World Journal}

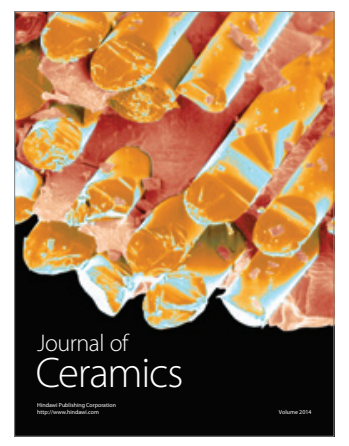

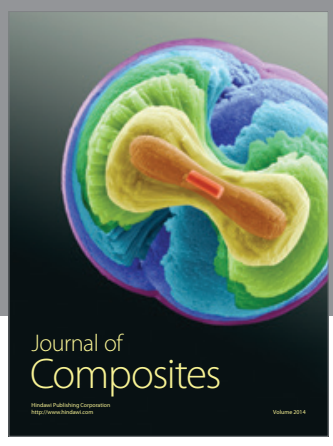
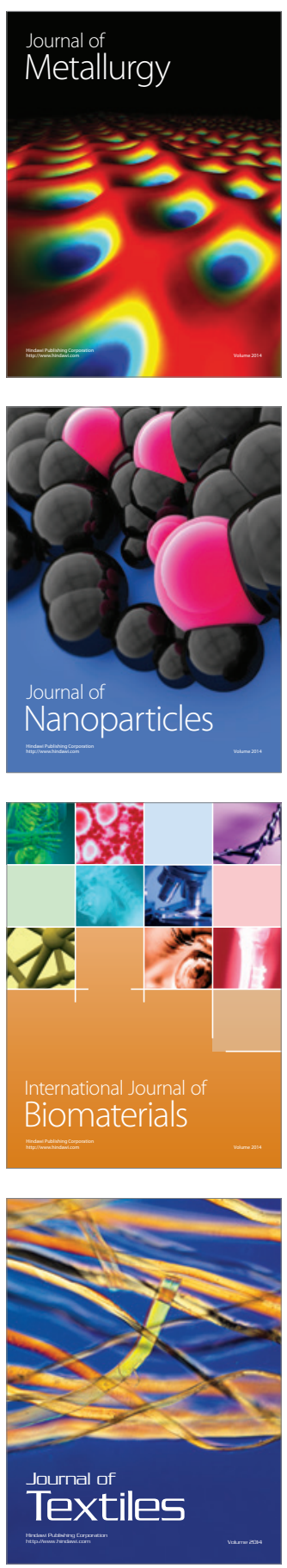